\title{
COMPLEMENTARY FEEDING PRACTICES AND NUTRIENT INTAKE FROM HABITUAL COMPLEMENTARY FOODS OF INFANTS AND CHILDREN AGED 6-18 MONTHS OLD IN LUSAKA, ZAMBIA
}

\author{
Owino $\mathrm{VO}^{1^{*}}$, Amadi $\mathrm{B}^{2}$, Sinkala $\mathrm{M}^{3}$, Filteau $\mathrm{S}^{4}$ and A Tomkins ${ }^{5}$
}

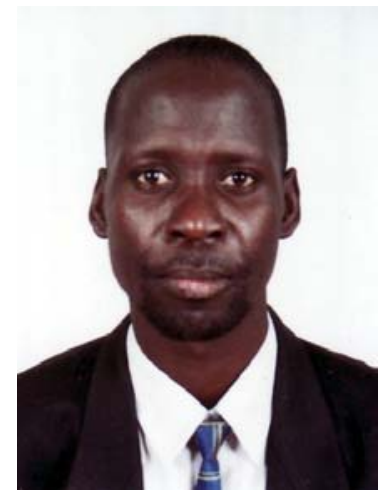

Victor Owino

*Corresponding author email: vowino@hotmail.com

${ }^{1}$ Victor O. Owino, PhD., Research \& Development Manager, Valid Nutrition, P.O. Box 20375-00200 Nairobi, Kenya. Tel: +254725625720.

Email: vowino@hotmail.com

${ }^{2}$ Beatrie Amadi, MMed., Department of Paediatrics and Child Health, University Teaching Hospital, P/Bag RW 1X Lusaka, Zambia. Email: bamadi@,zamtel.zm

${ }^{3}$ Moses Sinkala, Ph.D., Director, Lusaka District Health Management Board, P.O. Box 50827 Lusaka, Zambia. Tel: +260211235554. Email: msinkala@1ycos.com

${ }^{4}$ Suzanne Filteau, Ph.D., Professor of International Nutrition, London School of Hygiene and Tropical Medicine, United Kingdom. Room 183, North Courtyard, Keppel Street, London WC1E 7HT, UK. Tel: 02079588108.

Email: $\underline{\text { Suzanne.Filteau@1shtm.ac.uk }}$

${ }^{5}$ Andrew Tomkins, OBE., Professor of International Child Health, UCL Centre for International Health and Development, Institute of Child Health 30 Guildford Street London WC1N 1EH. Tel: +44 (0)207 905 2122. Email: a.tomkins@,ich.ucl.ac.uk 


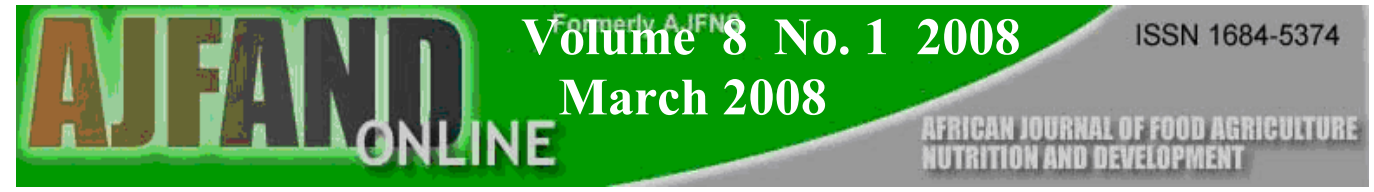

\begin{abstract}
Poor quality complementary foods with low nutrient density and inappropriate feeding practices have been identified among the major causes of malnutrition in young children. In many developing countries, complementary foods are introduced too early or too late and the quality and quantity of the foods are insufficient, leading to a great risk of nutritional deficiencies during the second half of infancy. Most of the habitually used complementary foods in developing countries are unfortified cerealbased gruels characterised by low energy and nutrient density and are often inadequate in iron, zinc and pyridoxine and in some populations may be deficient in riboflavin, niacin, calcium, thiamine, folate, ascorbic acid and vitamin A.
\end{abstract}

The aim of this study was to establish current complementary feeding practices of mothers/caretakers living in a medium income urban community in Lusaka, Zambia. The study was the first phase of a larger study designed to develop improved complementary foods based on already-in-use cereals and legumes for the improvement of infant health in urban settings characterised by high HIV prevalence. Complementary feeding practices and nutrient intakes of children 6-18 months old in Lusaka were assessed by qualitative and quantitative methods. Themes generated from three focus group discussions (9 health workers, 7 mothers and 8 fathers) were used to design a semi-structured questionnaire to interview 34 mothers, 20 of whom were observed for 12 hours at home and their infant's dietary intake measured by $12-\mathrm{h}$ weighed food record and 24-h recall, (assuming medium breast milk intake). The results showed that although mothers had wide knowledge of optimal infant feeding, actual practices were constrained by food cost, maternal HIV status and time availability. Compared with the recommended daily allowance (RDA) at 6-8, 9-11 and $12-18$ months of age, the daily nutrient intakes were $88 \%, 121 \%$ and $94 \%$ for energy; $33 \%, 52 \%$ and $59 \%$ for iron and $30 \%, 33 \%$ and $38 \%$ for calcium, respectively. Fortification of complementary foods is necessary to meet infants' needs for iron and calcium.

Keywords: Complementary feeding, infants, iron, Zambia. 


\section{INTRODUCTION}

Poor quality complementary foods with low nutrient density and inappropriate feeding practices have been identified as among the major causes of malnutrition in young children [1]. In many developing countries, complementary foods are introduced too early or too late and the quality and quantity of the foods are insufficient, leading to a great risk of nutritional deficiencies during the second half of infancy [2]. Most of the habitually used complementary foods in developing countries are unfortified cereal-based gruels characterised by low energy and nutrient density and are often inadequate in iron, zinc and pyridoxine and in some populations may be deficient in riboflavin, niacin, calcium, thiamine, folate, ascorbic acid and vitamin A $[3,4]$.

Food selection and preparation practices which affect food safety, nutrient density and feeding practices and maternal characteristics such as education, and socio-economic status have been identified as integral components of care-giving in relation to nutrition of young children [2]. The dearth of data on mother-infant interaction during feeding has been highlighted [2]. Such data may be used as the basis for education to cause change in feeding practices. Secondly, information on feeding practices may be used as the basis for complementary food design and promotion for the improvement of the nutritional status of infants and young children in resource poor settings.

The main aim of this study was to assess the complementary feeding practices and nutrient intakes of children aged $6-18$ months old in urban Lusaka as a prelude to the development and evaluation of the acceptability of a multi-micronutrient fortified maize-bean complementary food.

\section{METHODS}

The study was based at Chilenje clinic in Lusaka, Zambia, a medium income urban area where most households have running water and flush toilets. Chilenje clinic was chosen since the study was the initial phase of a larger study that aimed to assess the benefits of improved complementary foods among an urban population that could afford such foods. Ethical approval was obtained from the University of Zambia Ethics Committee and Great Ormond Street Hospital, UK.

Qualitative data were obtained, based on convenience sampling, using three main techniques, namely, focus group discussions, interviews and home observations in order to allow for the triangulation of findings as described previously [5]. A qualitative approach was chosen to obtain information on knowledge, attitude and complementary feeding practices that could not be measured by standard quantitative methods [5]. Secondly, findings obtained by qualitative methods were used as the basis for the subsequent stage of complementary food development. Quantitative data were obtained by 24-hr dietary recall and 12-hr weighed food record. All participants gave written consent to attend the focus group discussions and had the ability to speak English. The requirement that participants be able to speak English was not a major

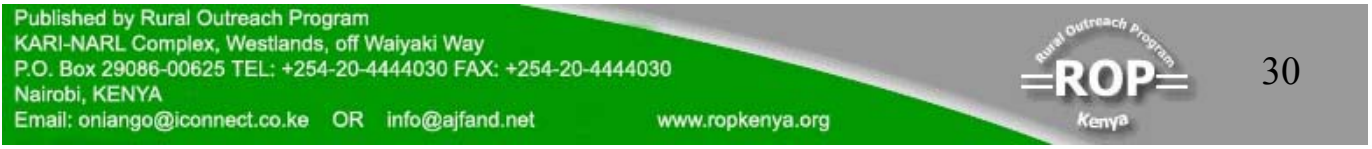


source of bias as English is the official language in Zambia and schooling is in English.

\section{Focus group discussions}

Three focus group discussion sessions were held at Chilenje clinic with the help of two trained assistants (nutritionist and nurse) to assess current complementary feeding practices, attitudes and beliefs that would influence any nutritional intervention based on the provision of improved complementary foods. The three groups attending the discussions were: 1) 9 health workers from Chilenje clinic; 2) 7 mothers from Chilenje who had children aged 6-18 months 3) 8 fathers from Chilenje who had children aged 6-18 months. These three groups were chosen because they had direct involvement in child care and complementary feeding decision making process. Individual mothers, nurses and fathers were invited by one of the assistants who had good rapport with the Chilenje community based on her involvement in a previous project by our group. Focus group themes were explored using the same question guide for all the three focus groups discussion sessions. Proceedings of each discussion were recorded in note books by the first author and one assistant and on audio cassette which was later transcribed. Generated themes were used to design the semi-structured questionnaire for formal interviews.

\section{Interviews}

A total of 34 mothers of infants 6-18 months old were interviewed by the first author and two assistants using a semi-structured questionnaire that had been pre-tested at Chilenje clinic with three mothers of infants of the same age group (6-18 months). Participants were invited by the two trained assistants as they brought their children for growth monitoring at the clinic. The main inclusion criteria were that the mother was able to speak English and gave informed consent. The purpose of the interviews was to assess the availability and factors affecting the use of cereals and legumes and commercial complementary foods in addition to complementary feeding practices, knowledge, beliefs and attitudes. The questionnaire was divided into three main sections concerning household characteristics, food availability, and infant feeding and care practices. The third section was divided into four subsections namely, breastfeeding practices, infant care and time availability, complementary feeding practices, and food preparation and handling. All mothers were asked after the interviews if they would give consent for home visits after two weeks; 20 mothers gave written consent: 7 with infants 6-8 months, 6 with infants 9-11 months and 7 with children 12-18 months.

\section{Home observations}

The 20 mothers were observed at home for 12 hours during daylight by the first author accompanied by a female nurse. Although this approach provides first hand information, it is intrusive and the results may be biased due to change of behaviour by the subject in the presence of an observer $[6,7,8]$. Mothers were asked to continue with their normal routines while the researchers determined their actual food preparation and handling behaviour and how they fed their children. Dietary intake was determined by 12-h weighed food record for the day of the visit and 24 h-recall for the day preceding the observation. Weighed food record data were used to

Published by Rural Outreach Program
KARI-NARL Complex, Westlands, off Walyaki Way
P.O. Box 29086-00625 TEL: +254-20-4444030 FAX: $+254-20-4444030$
Nairobi, KENYA
Email: oniango@iconnect.co.ke OR info@ajfand.net mww.ropkenya.org


calculate the daily intake of energy, iron, and calcium based on a Zambian food composition table [9]. Medium breast milk intake was assumed based on the latest World Health Organization (WHO) estimates for children 6-23 months old [10]. Data for iron absorption from complementary foods and breast milk and the recommended dietary allowance (RDA) for absorbable iron were taken from the current WHO estimates [11]. Low iron absorption $(2.4-6 \%)$ from maize-based diets was assumed. Daily amounts of absorbable iron obtained from breast milk were assumed to be $0.11 \mathrm{mg} /$ day and $0.09 \mathrm{mg} /$ day for children 6-12 months and 13-18 months, respectively [11]. The daily intake of calcium from breast milk was assumed to be $130 \mathrm{mg}$, the estimate for children 6-23 months old and calcium retention from breast milk and solid foods was assumed to be $50 \%$ and $20-25 \%$, respectively [10].

Energy and absorbable iron obtained from $12 \mathrm{~h}$ weighed food record and $24 \mathrm{~h}$ recall of the day preceding the observation were compared. A total of 10 and 9 porridge recipes obtained by $12 \mathrm{~h}$ weighed food record and $24 \mathrm{~h}$ recall, respectively were compared.

\section{Data analysis}

Data analysis was performed by the first author based on previous guidelines $[6,12]$. Tape records of the three focus group discussions were transcribed verbatim and combined with a review of notes that were taken by the researcher and an assistant. The transcripts were coded into major themes that were generated manually. Internal validity was ensured by combining focus group discussions with interview and home observation data. In addition, peer examination of the transcripts was done by an African nurse with experience in nutrition who was not directly connected with the study. Quantitative data from home observation were double entered using Epi Info (version 3.2, Center for Disease Control and Prevention, WHO, 2002). Frequencies, means and median values were calculated using SPSS software (version 11.6).

\section{RESULTS}

\section{Focus Group Discussion Themes}

Five major focus group discussion themes were generated: 1) breastfeeding and timing of weaning; 2) food availability and affordability (see Box 1); 3) food beliefs and attitudes; 4) food choice and avoidance (see Box 2); and 5) food preparation (see Box 3). 


\section{Box 1}

\section{Theme 1: breastfeeding and timing of weaning}

Quotes

"...normally six months they introduce [complementary foods], but in

between you breastfeed, like five times a day" (father).

"...it is our duty to breastfeed on demand" (mother).

"... any time when the baby wants to breastfeed for those who are not working"' (nurse).

“... yes it is understood it [breast milk] has all the nutrients, but to supplement to satisfaction of the baby you need more food, the baby needs solids" [father].

“... when baby cries a lot, they can start at one month because child is hungry" (mother).

. "... sometimes it is at the clinic, where they tell mothers the right thing, like me it was the Sister" (mother).

"...when mothers go to the clinic, from knowledge from clinic, babies should introduce foods after six months" (father).

"... the caretakers, the mother is at work, so the caretaker decides to give [solid foods]" (nurse).

"... these days it is the [mother's HIV] status that matters" (mother).

\section{Theme 2: Food availability and affordability}

Quotes

"... whatever is available in the family, even biscuits" (nurse).

"...groundnuts, it depends on the season, like now [September] it is expensive" (mother).

"I have never used them [commercial complementary foods] because I cannot afford... they are not very common to all, may be a few families, ...those who can afford them use them, if they are available they are used, they are there in the shop, people are buying them, but not us" (nurse). 
Box 2. Focus group themes 3 and 4.

Theme 3: Food beliefs and attitudes

Quotes

“... some think with maize meal porridge their children may suffer from stomach problems, so they give Cerelac and Vitaso" ' [commercial infant foods] (mother).

“... rich people feed with expensive foods, they think groundnuts are for poor people, people will laugh" (mother).

"I have never believed in them [commercial complementary foods] simply because I have never witnessed some being prepared, secondly, I never know how long they have been standing in the shelf and since I believe in food prepared at home, that is why I have never taken my time to go out and give my children things from the shop" (nurse).

"... you cannot be sure they put everything they indicate on the boxes" (mother).

"I think some people think those which are already made they are not very good because even the ingredients, they just dry it, they are not there, they are not even meant for babies, they just put baby there and say these are for baby" (father).

\section{Theme 4: Food choice and avoidance}

Quotes

"... any food as long as it has the vitamins required for her" (mother).

"... like what I have done with my daughter, I always use a bit of milk with sugar, and if I have money I add some soya" (father). 


\section{Box 3. Focus group theme 5: Food preparation}

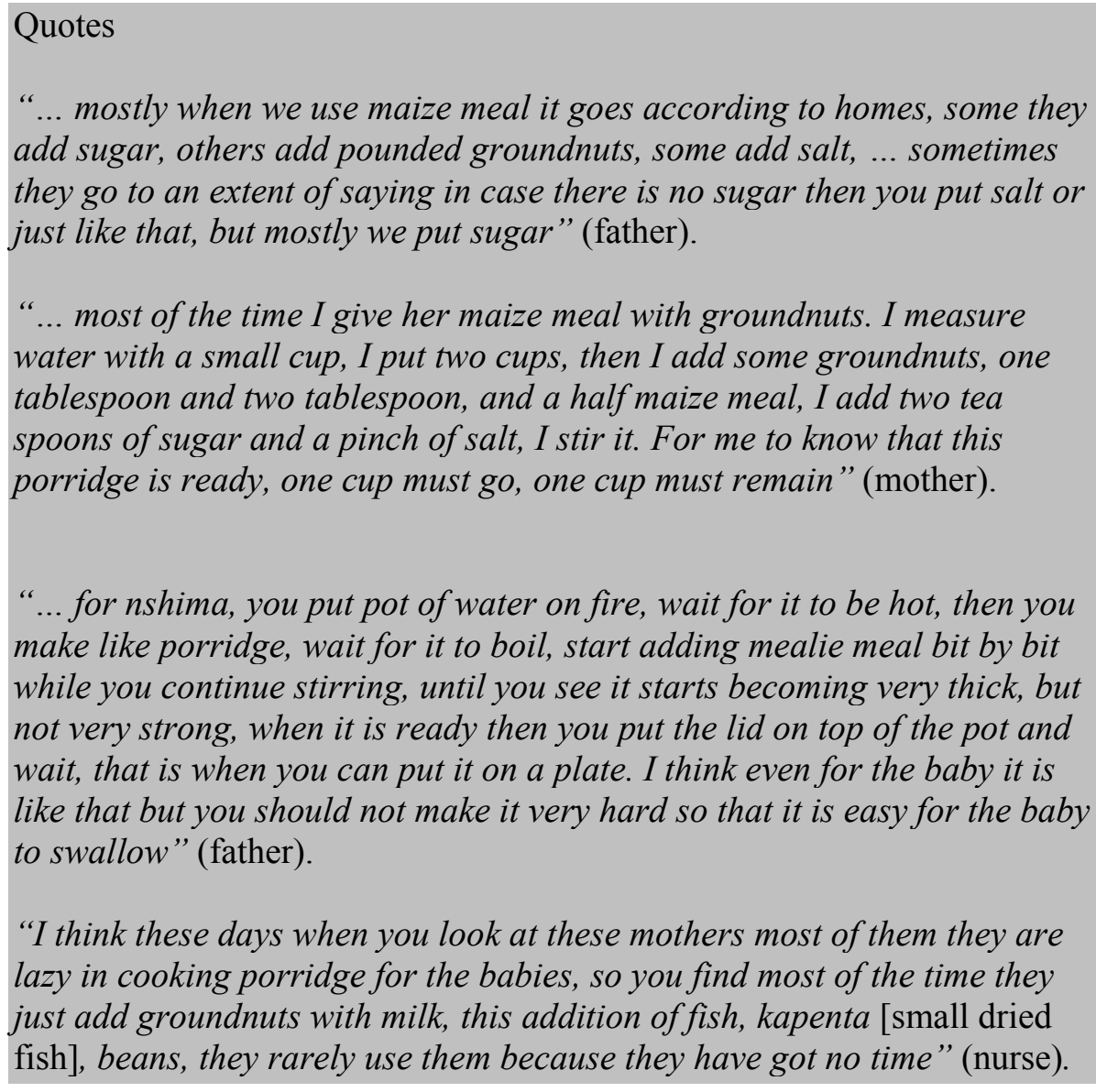

“... for nshima, you put pot of water on fire, wait for it to be hot, then you make like porridge, wait for it to boil, start adding mealie meal bit by bit while you continue stirring, until you see it starts becoming very thick, but not very strong, when it is ready then you put the lid on top of the pot and wait, that is when you can put it on a plate. I think even for the baby it is like that but you should not make it very hard so that it is easy for the baby to swallow" (father).

"I think these days when you look at these mothers most of them they are lazy in cooking porridge for the babies, so you find most of the time they just add groundnuts with milk, this addition of fish, kapenta [small dried fish], beans, they rarely use them because they have got no time" (nurse).

\section{Breastfeeding and timing of weaning}

There was wide knowledge of the benefits of breastfeeding for the first two years of life. The need to feed on demand was also supported, especially for younger infants and in cases where mothers were not working outside the home. Even though there was understanding of the benefit of breastfeeding, there were doubts as to the nutritional adequacy of breast milk. Complementary foods were introduced mostly when the child attained $4-6$ months; however, the age of introducing these foods ranged from $1-9$ months. Factors determining the timing of complementary foods included baby crying, and baby not being satisfied. The other factors were advice from the health clinics and the necessity for some mothers to return to work. Knowledge of maternal HIV status was also mentioned as one of the factors that may lead to early introduction of complementary foods. 


\section{Food availability and affordability}

The main foods available for feeding infants included maize meal, rice, groundnuts, beans, fish, milk and fruits (bananas, oranges, pawpaw) and vegetables (carrots, pumpkins, green vegetables). The child's food was determined by what was available in the household, the cost of food and seasonality. Even though commercially processed complementary foods were also available in the market, their use for feeding infants was restricted by the high prices.

\section{Food beliefs and attitudes}

There was preference for foods prepared at home as mothers felt that they were fresher and that they contained all the nutrients. However, there was also acknowledgement that some of the foods (such as okra prepared using sodium bicarbonate and cold foods) prepared at home may cause stomach problems in the child. The use of traditional foods as opposed to commercially prepared foods was thought to be more common among poorer households. There was acknowledgement that commercially processed complementary foods were easy to prepare and some participants felt they were better than what they prepared at home. However, the use of these foods was hampered by mistrust of their freshness and nutritional completeness.

\section{Food choice and avoidance}

Food choice was affected mainly by the food's nutritional value, availability, child's age and cost. Other factors included expiry date and temperature. There was emphasis among focus group participants on the provision of a varied diet. With additional income, households buy foods they consider more nutritious. Foods were considered bad if they were carbonated, spiced, acidic or too sweet.

\section{Food preparation}

The main food for infants was porridge that was prepared in different ways depending on ingredient availability. Cooking of porridge lasted $20-45$ minutes. The other major food for infants is nshima (a stiff porridge from maize meal) and is prepared such that the child can easily swallow it. Mother's availability had a major effect on what food the babies were fed, how these foods were prepared and meal frequency.

\section{Interviews}

Table 1 shows the selected demographic characteristics of the 34 interview subjects. Most (62\%) of the households had 2-3 children and $32 \%$ of the households had another child aged below 5 years. Table 2 presents breastfeeding and complementary feeding practices of interviewed mothers. A majority of the mothers $(88 \%)$ were still breastfeeding. Foods other than breast milk were introduced into the infant's diet at an average age of 6 (SD 2) months of age, indicating that mothers were complying with breastfeeding guidance. Cessation of breastfeeding was at the age of 19 (SD 4) months. The choice of which solid food the infant was fed on was based on mother's perceived nutritional value of the food.

Published by Rural Outreach Program
KARI-NARL. Complex, Westlands, off Walyaki Way
P.O. Box 29086-00625 TEL: +254-20-4444030 FAX: +254-20-4444030
Nairobi, KENYA
Email: oniango@iconnect.co.ke OR info@ajfand.net mww.ropkenya.org


Use of legumes, cereals and pre-packed complementary foods, and food preparation

For preparation of infant foods, all mothers used maize, beans and groundnuts, while a third of mothers used bambara nuts and pre-cooked soya flour. Maize-meal-based porridge was the main form of food for infants. Porridge was prepared with the addition of any or more of the following ingredients to maize meal: pounded groundnuts, cooking oil, sugar, fresh milk, salt, eggs and custard powder. The main pre-packed multi-micronutrient fortified cereal-based complementary foods available in Lusaka were high energy protein supplement (HEPS, a maize-soya food mainly used as food aid in relief operations), Speciality Vitaso ${ }^{\mathrm{TM}}$, Speciality Nutrex ${ }^{\mathrm{TM}}$ and Cerelac $^{\mathrm{TM}}$. These foods are mainly targeted to children from 6 months to 4 years of age. The average price per kilogram for these foods was found to be US\$ 4.6 (SD 2.4) and most mothers in Chilenje could afford them.

\section{Cash expenditure on food and fuel}

The mother's ability to purchase food for their child was determined mainly by educational attainment, which may have affected salary levels, and marital status. Mothers who had attained primary, secondary and tertiary level of education made spending decisions in $25 \%, 32 \%$ and $83 \%$ of the cases, respectively. While married mothers made spending decisions in only $27 \%$ of cases, single mothers decided in $75 \%$ of cases. Eighty two percent of mothers used electric hot plates for cooking, while $18 \%$ used charcoal. The mean monthly electricity cost was USD 12. Lack of electricity occurred mostly twice a week, but this became worse during rains and $59 \%$ of mothers recalled having experienced electricity failure in the month prior to the interview.

\section{HOME OBSERVATIONS}

\section{Dietary intake}

Table 3 presents the daily intake of energy from habitual complementary foods measured by $12 \mathrm{~h}$ weighed food records, and $24 \mathrm{~h}$ recall, and from breast milk for infants 6-8 months, 9-11 months, and young children aged 12-18 months old. Energy intakes obtained by $12 \mathrm{~h}$ weighed food record and $24 \mathrm{~h}$ recall were comparable. However, the food solids intake values obtained by $12 \mathrm{~h}$ weighed food record were higher than those obtained by $24 \mathrm{~h}$ recall. The mean energy density based on recipes from $12 \mathrm{~h}$ food record and $24 \mathrm{~h}$ recall of home porridges was 3.8 (SD 1.1) $\mathrm{kJ} / \mathrm{ml}$ and 3.5 (SD 1.1) $\mathrm{kJ} / \mathrm{ml}$, respectively for recipes obtained by $12 \mathrm{~h}$ weighed food record and $24 \mathrm{~h}$ recall.

The average daily complementary food intake was $127 \mathrm{~g} \mathrm{(95 \%} \mathrm{CI,} \mathrm{82.7,} \mathrm{171.3)} \mathrm{for} \mathrm{the}$ three age groups. The average daily intake of protein and fat were $10.6 \mathrm{~g}(95 \% \mathrm{CI}$, $5.2,16.0)$ and $11.6 \mathrm{~g}(95 \% \mathrm{CI}, 6.3,16.8)$, respectively, representing $107 \%$ and $179 \%$ of RDA for protein and fat, respectively, for children aged $6-18$ months. Table 4 shows the daily intake of thiamine, riboflavin, niacin, vitamin $\mathrm{A}$, iron and calcium from complementary foods calculated from $12 \mathrm{~h}$ weighed food record and $24 \mathrm{~h}$ recall and breast milk for infants and young children 6-18 months old. While most of the micronutrient intake results were comparable for the two methods, values for

Published by Rural Outreach Program
KARI-NARL Complex, Westlands, off Waiyaki Way
P.O. Box29086-00625 TEL: +254-20-4444030 FAX:+254-20-4444030
Nairobi, KENYA
Email: oniango@iconnect.co.ke OR info@ajfand.net mw.ropkenya.org


thiamine, riboflavin and calcium were lower when $12 \mathrm{~h}$ weighed food record was used. The mean absorbable iron density of the porridges was 3.0 (SD1.6) $\mu \mathrm{g} / \mathrm{ml}(95 \% \mathrm{CI}$, $2.0,4.0)$ and $4.5(\mathrm{SD} \mathrm{3.1)} \mu \mathrm{g} / \mathrm{ml}(95 \% \mathrm{CI}, 2.5,6.5)$, respectively for recipes obtained by $12 \mathrm{~h}$ weighed food record and $24 \mathrm{~h}$ recall.

\section{Infant feeding and care}

In most cases (70\%), the mother fed the child. The rest of the time the child was fed by the grandmother, sibling or house-help. The feeding location was predominantly $(75 \%)$ in the sitting area of the family house with the child held on the mother/caretaker's lap. Verbal encouragement was observed in $74 \%$ of the cases, and in most cases was occasioned by the child's refusal to eat. Predominant silence with occasional encouragement or coaxing was observed in $26 \%$ of the cases. Feeding utensils comprised plastic cups and spoons for porridge. Other foods were served on plastic plates and fed by hand. Most mothers (68\%) did not store leftover food, which in most cases was eaten by an older member of the family (mother, sibling or any other member of the household).

\section{DISCUSSION}

The dietary data show that energy and macronutrient intakes of infants and young children in this population were generally adequate, but that intakes of certain minerals, particularly iron, calcium and zinc, were inadequate. The strong support for breastfeeding by mothers, fathers and health workers contributed to the adequate intakes of many nutrients. However, in order to improve infant nutrition in Lusaka, it may be necessary to develop and promote fortified complementary foods which are acceptable to and affordable by families since they are produced based on locally grown cereals and legumes.

The focus group discussion results show that even though some mothers use commercially processed complementary foods to feed their children, most mothers, including well educated people, regard these foods with suspicion. This is mainly with regard to how long the foods have been on the shelf. Most of the existing commercially processed foods in Lusaka cost on average US\$ 4 per kilogram pack since they are largely based on imported ingredients based on milk powder. Most mothers in Chilenje could not afford these foods. Engagement in work outside the home was a constraint on the length of time the mother spent on child feeding and care. Food that is considered good on the basis of its nutritional value and freshness and that which can be readily prepared had potential market among Chilenje mothers.

The wide support for breastfeeding is supported by the observation that only 2 of the mothers introduced complementary foods due to reported perception of lack of enough breast milk. The median age for the introduction of complementary foods was 6 months as recommended [13], but some mothers introduced these foods too early at 2 months and some too late at 12 months. The acknowledgement of maternal HIV status as a determining factor for the early introduction of complementary foods supports previous observations that knowledge that HIV can be transmitted through

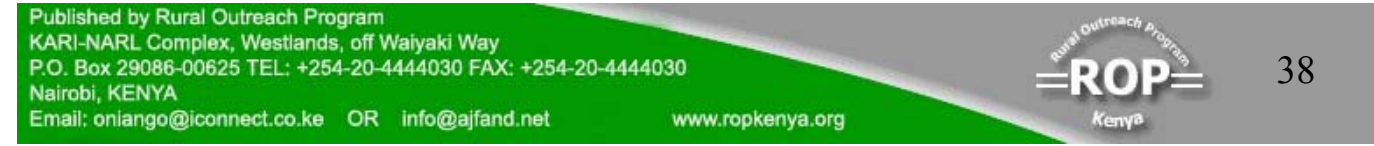


breastfeeding results in decreased levels of breastfeeding [14]. This may reflect a response to current recommendations for abrupt cessation of breastfeeding for HIVinfected mothers in cases where affordable, feasible, acceptable, sustainable and safe replacement feeding is available [13]. Other work from our group [15] showed that HIV-infected primiparous women stop exclusive breastfeeding earlier than other women in Chilenje, suggesting that there is confusion about what is the best feeding practice for HIV-infected women in resource poor settings where the strict criteria for replacement feeding may not be easily met. Fear of disclosure of HIV status and stigma may lead to too early introduction of fluids and other foods as reported from South Africa [16]. Further, emerging evidence indicates that some mothers who know that they are HIV-infected still continue to breastfeed even in cases where there is counselling on infant feeding options [17]. This has been attributed to lack of openness among partners, fear of stigma in the community lack of knowledge and lack of money to buy replacement formulas [16-19]. A recent review further highlighted difficulties in constructing a nutritionally adequate diet for the nonbreastfed child in low income settings [20].

The observation that mothers/caretakers encouraged the child to eat only when the child was not eating well is contrary to the currently recommended responsive feeding [21] that entails feeding with positive verbal encouragement, without physical or verbal coercion [2]. The fact that most feeding sessions took place in the living room could result in interruption of feeding by visitors and entertainment media such as television. The significance of a feeding environment free of distraction for adequate nutrient intake has been underscored [2]

The observed daily intake of food solids is within the range of $25 \mathrm{~g}$ to $250 \mathrm{~g}$ reported earlier for developing countries [10]. The observed total intake of absorbable iron and calcium fell short of recommended values $[10,11]$. The observed intake of iron in the current study is consistent with recent observations from Tanzania [22] that complementary foods provided $15 \%, 20 \%$ and $27 \%$ of iron requirements for infants 6 8, 9-11 months and young children 12-23 months, respectively. The current results also support recent findings from South Africa [23] that complementary foods were inadequate in iron, zinc and calcium.

The observed high intakes of vitamin A can be attributed to the fact that in Zambia sugar is fortified with vitamin A at a minimum rate of $10 \mathrm{mg} / \mathrm{kg}$ [24]. From 24h-recall data, sugar formed $20 \%$ of porridge dry recipe. It is estimated that vitamin A intake from sugar in the three groups accounted for $63 \%$ of the total vitamin A intake from complementary foods. This finding is consistent with the results of evaluation studies on the effect of sugar fortification on vitamin A status in Zambia [24]. Since vitamin $\mathrm{A}$ is classified as one of the problem micronutrients in developing countries, the Zambian model of fortifying sugar with vitamin A may be used in other countries [25]. However, sugar may not be affordable to most households in poor settings and may thus not be the best vehicle for vitamin A. Micronutrient capsules or sprinkles may be more appropriate for poor settings [25]. 
Inadequate intakes of iron, calcium and zinc augment previous observations that these three micronutrients are among 'problem nutrients' in developing countries [25] even in cases where strategies to improve their bioavailability are employed [26]. A recent double-blind, randomized placebo-controlled study from Tanzania [22] showed that improved iron solubility and energy density of a complementary food processed using germinated and autoclaved finger millet-kidney beans, roasted peanuts and mango puree had no effect on growth, haemoglobin and iron status of children 6-12 months old. The workers concluded that the slight improvement in iron solubility as a result of processing was not sufficient to offset the low iron content of the complementary food. A study from Bangladesh reported inadequate intake of vitamins and minerals among breast-fed infants 6-12 months old and attributed this to low micronutrient density of complementary foods [27].

The findings of the current study strongly support previous recommendations that multi-micronutrient fortification of complementary foods is required if the needs for 'problem nutrients' like iron, calcium and zinc are to be met, especially for nonbreastfed infants after the first 6 months of life.

\section{ACKNOWLEDGEMENTS}

We acknowledge the support of the entire staff of the Breast Feeding and Postpartum Health Project throughout the study. We are grateful for the assistance in data collection by Molly Chisenga, Lungowe Nyaywa, Mutinta Muzyamba and Tamara Kavimba and in analysing qualitative data by Rachel Rori. We also acknowledge the contribution of Rhoda Zulu, National Institute for Scientific and Industrial Research, Lusaka for her critique of this manuscript. We are grateful to Score Africa for the financial support. 


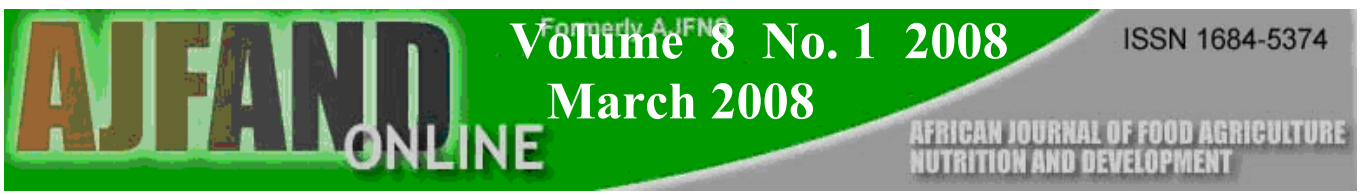

Table 1: Selected demographic characteristics of the mothers interviewed $(\mathrm{n}=34)$.

Variable

$\mathbf{N}$

\section{Child's sex}

Boys

$18(53 \%)$

Girls

$16(47 \%)$

\section{Child's age (mo)}
6-8
$11(32 \%)$
9-11
$10(30 \%)$
12-18
$13(38 \%)$
Mother's age (years)
26 (SD 7)

\section{Marital status}

Married

$26(76 \%)$

Single

$8(24 \%)$

Mother's education

Primary (1-7 grades)

$8(23 \%)$

Secondary (8-12 grades)

$19(56 \%)$

Tertiary college

$7(21 \%)$

\section{Mother's occupation}

Salaried employed

$5(15 \%)$

Self-employed

$4(12 \%)$

Housewife

$22(65 \%)$

Unemployed

$3(8 \%)$ 
Table 2: Breastfeeding and complementary feeding practices determined by interviewing 34 mothers

Mothers currently breastfeeding $\quad 88 \%$

Frequency of breastfeeding

Day light $\quad 7$ (SD 4)

Night 5 (SD 3)

Child's age (months) when mother plans to

stop breastfeeding

$19(\operatorname{SD} 4)$

Percent mothers feeding other milks $\quad 53 \%$

Feeding fresh cow's milk $\quad 44 \%$

Feeding Lactogen $^{\mathrm{TM}} \quad 6 \%$

Other tinned powdered milk $\quad 3 \%$

Infant's age (months) at which complementary foods are introduced 6 (SD 2)

Reason for introducing complementary foods at particular age

Child crying $32 \%$

Advice from health worker $\quad 23 \%$

Lack of enough breast milk $\quad 6 \%$

Advice from relatives $\quad 6 \%$

Child old enough $\quad 6 \%$

Mother working $\quad 9 \%$

Most important factor considered in food choice for infants

Nutritional value $\quad 53 \%$

$\begin{array}{ll}\text { Freshness } & 26 \%\end{array}$

Food temperature $\quad 23 \%$

Child's age $\quad 12 \%$

Child's food preference $\quad 12 \%$

Daily cooking frequency (infant's food) 3

Range of porridge cooking duration (minutes) $\quad 30-60$ 


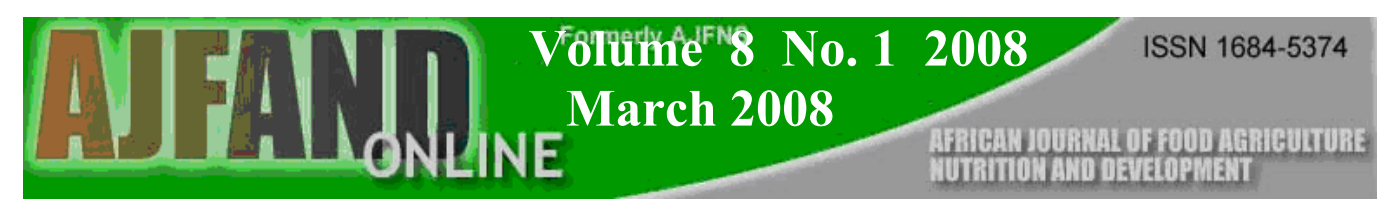

Table 3: Daily energy intake (MJ/day) from habitual complementary foods calculated from $12 \mathrm{~h}$ weighed food record and 24h recall and from breast milk for infants 6-8, 9-11 months and young children 12-18 months old.

\begin{tabular}{|c|c|c|c|c|c|c|}
\hline & \multicolumn{6}{|c|}{ Age range } \\
\hline & \multicolumn{2}{|c|}{$6-8$ months } & \multicolumn{2}{|c|}{ 9-11 months } & \multicolumn{2}{|c|}{$\underline{12-18 \text { months }}$} \\
\hline & $\begin{array}{l}\text { 12h weighed } \\
\text { food record }\end{array}$ & $24 \mathrm{~h}$ recall & $\begin{array}{l}\text { 12h weighed } \\
\text { food record }\end{array}$ & $24 \mathrm{~h}$ recall & $\begin{array}{l}\text { 12h weighed } \\
\text { food record }\end{array}$ & $24 \mathrm{~h}$ recall \\
\hline $\begin{array}{c}\text { Energy intake } \\
\text { (MJ/day) }\end{array}$ & & & & & & \\
\hline Complementary foods & 1.2 & 1.4 & 2.7 & 2.0 & 2.9 & 2.0 \\
\hline energy [mean $(95 \% \mathrm{CI})]$ & $(0.6 ; 1.7)$ & $(0.9 ; 1.9)$ & $(0.9 ; 3.2)$ & $(1.6 ; 2.5)$ & $(0.9 ; 4.3)$ & $(1.0 ; 3.0)$ \\
\hline Breast milk energy $^{1}$ & \multicolumn{2}{|c|}{1.7} & \multicolumn{2}{|c|}{1.6} & \multicolumn{2}{|c|}{1.4} \\
\hline Percent RDA & 112 & 119 & 151 & 127 & 115 & 91 \\
\hline
\end{tabular}

${ }^{1}$ Values are for medium breast milk intake taken from reference [25]

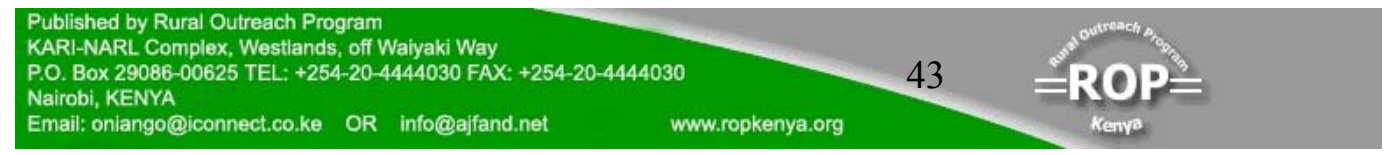




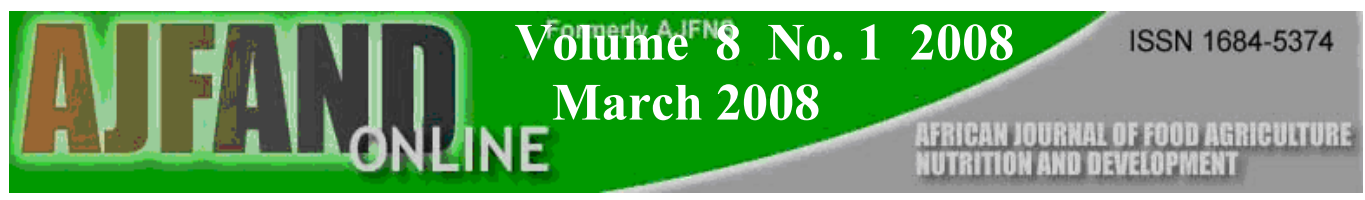

Table 4: Daily intake of thiamine, riboflavin, niacin, vitamin A, iron and calcium from complementary foods calculated from $12 \mathrm{~h}$ weighed food record and $24 \mathrm{~h}$ recall breast milk for infants and young children 6-18 months old.

\begin{tabular}{|c|c|c|c|c|c|c|c|}
\hline & $\begin{array}{l}\text { Thiamine } \\
\text { (mg) }\end{array}$ & $\begin{array}{l}\text { Riboflavin } \\
\quad(\mathrm{mg})\end{array}$ & $\begin{array}{l}\text { Niacin } \\
(\mathrm{mg})\end{array}$ & $\begin{array}{c}\text { Vitamin } \\
\text { A } \\
(\mu \mathrm{g})\end{array}$ & $\begin{array}{l}\text { Iron }^{2} \\
(\mathrm{mg})\end{array}$ & $\begin{array}{l}\text { Calcium } \\
\text { (mg) }\end{array}$ & $\begin{array}{l}\text { Zinc } \\
(\mathrm{mg})\end{array}$ \\
\hline \multicolumn{8}{|c|}{$\begin{array}{l}\text { From complementary } \\
\text { foods [mean }(95 \% \\
\text { CI)] }\end{array}$} \\
\hline 12-h record & $\begin{array}{c}0.3 \\
(0.1,0.4)\end{array}$ & $\begin{array}{c}0.2 \\
(0.1,0.6)\end{array}$ & $\begin{array}{c}2.7 \\
(1.1,4.9)\end{array}$ & $\begin{array}{c}185 \\
(73,341)\end{array}$ & $\begin{array}{c}0.2 \\
(0.06,0.3)\end{array}$ & $\begin{array}{l}44 \\
(9.7,65)\end{array}$ & $\begin{array}{c}2.2 \\
(1.7,3.4)\end{array}$ \\
\hline 24-h recall & $\begin{array}{c}0.4 \\
(0.2,0.6)\end{array}$ & $\begin{array}{c}0.3 \\
(0.2,0.5)\end{array}$ & $\begin{array}{l}3.4 \\
(1.4,5.3)\end{array}$ & $\begin{array}{l}165 \\
(72,258)\end{array}$ & $\begin{array}{c}0.2 \\
(0.08,0.2)\end{array}$ & $\begin{array}{l}121 \\
(29,214)\end{array}$ & $\begin{array}{l}2.0 \\
(1.5,2.8)\end{array}$ \\
\hline Breast milk ${ }^{1}$ & 0.13 & 0.13 & 1.1 & 307 & 0.1 & 130 & 0.3 \\
\hline \multicolumn{8}{|l|}{ Percent RDA } \\
\hline 12-h record & 124 & 78 & 88 & 131 & 55 & 34 & 61 \\
\hline 24-h recall & 161 & 109 & 79 & 129 & 54 & 54 & 56 \\
\hline
\end{tabular}

${ }^{1}$ Values are for average breast milk intake taken from reference [25]

${ }^{2}$ Average iron absorption from non-breast milk foods assumed to be $4 \%$. Range of iron absorption for maize-based meals is 2.4-6\%. Results were calculated by dividing total daily iron intake by absorbable iron RDA: $0.58 \mathrm{mg} /$ day and $0.54 \mathrm{mg} /$ day for infants 7-12mo and children 13-24mo [11].

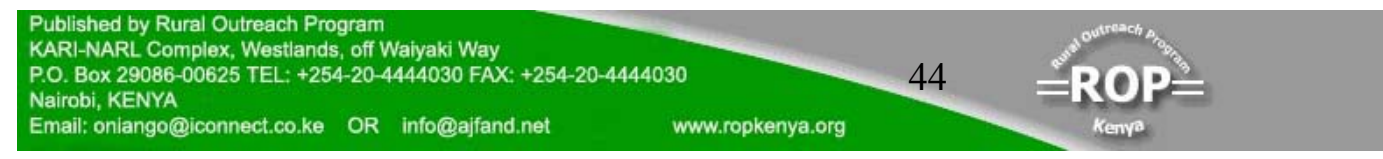




\section{REFERENCES}

1. World Health Organization. Forward. Food Nutr. Bull. 2003; 24: 3-4.

2. Pelto GH, Levitt $\mathbf{E}$ and Lhairu Improving feeding practices: current patterns, common constraints, and the design of interventions. Food Nutr Bull. 2003; 24: 45-82.

3. Hotz C and RS Gibson Complementary feeding practices and dietary intakes from complementary foods amongst weanlings in rural Malawi. Eur J Clin/ Nutr. 2001; 55: 841-9.

4. Lutter CK and JA Rivera Nutritional status of infants and young childrenand characteristics of their diets. J Nutr. 2003; 133: 2941S-9S.

5. Pope $\mathbf{C}$ and $\mathbf{N}$ Mays Reaching the parts other methods cannot reach: an introduction to qualitative methods in health and health services research. BMJ. 1995; 311: 42-5.

6. Creswell JW A qualitative approach. In: Research design: quantitative and qualitative approaches. Sage Publications, Washington DC. 1994: 150.

7. Gibson RS and EL Ferguson Assessing dietary zinc in a population. Am J Clin Nutr. 1998; 68 (Suppl): 430S-4S.

8. Gibson RS and EL Ferguson An interactive 24-hour recall for assessing the adequacy of iron and zinc intakes in developing countries. ILSI Press. Washington DC. 1999.

9. National Food and Nutrition Commission. Food composition tables for use in Zambia ( $2^{\text {nd }}$ ed.). National Food and Nutrition Commission. Lusaka. 1997. pp 51.

10. Lutter CK and KG Dewey Proposed nutrient composition for fortified complementary foods. J Nutr. 2003; 133: 3011S-3020S.

11. Lynch SR and RJ Stoltzfus Iron and ascorbic acid: proposed fortification levels and recommended iron compounds. J Nutr. 2003; 133: 2978S-2984S.

12. Kitzinger J Introducing focus groups. BMJ. 1995; 311: 299-302.

13. World Health Organization. Infant and young child nutrition: Global strategy for infant and young child nutrition. WHO, Geneva. 2002. pp 37. 
14. Omari AAA, Luo C, Kankasa C, Bhat GJ and J Bunn Infant-feeding practices of mothers of known HIV status in Lusaka, Zambia. Health Policy and Planning 2003; 18: 156-162.

15. Chisenga M, Kasonka L, Makasa M, Sinkala M, Chintu C, Kaseba C, Kasolo F, Tomkins A, Murray S and S Filteau Factors affecting the duration of exclusive breastfeeding among HIV-infected and uninfected women in Lusaka, Zambia. J Hum Lact. 2005; 21 (3): 266-275.

16. Doherty T, Chopra M, Nkonki L, Jackson D and T Greiner Effect of the HIV epidemic on infant feeding in South Africa: "When they see me coming with the tins they laugh at me". Bull World Health Organ. 2006; 84 (2): 90-6.

17. Chisenga M, Ngulube M, Kasonka L, Sinkala M, Filteau S and ATomkins Infant feeding, child survival, reproductive choice and anti retroviral treatment among HIV infected women in Lusaka, Zambia. SAJCN. 2005; 49 (Suppl 1): 243.

18. Kiamba JM, Hendriks S, Ntuli SM and S Cengimbo Infant feeding practices in Kwazulu-Natal, South Africa. SAJCN. 2005; 49 (Suppl 1): 246.

19. Petrie KEM, Schmidt SD, Schwarz CE, Koornhof HE and D Marais Knowledge, attitude, and practices of mothers on the prevention of mother-tochild transmission (PMTCT) programme at the Vanguard Community Health Centre, Western Cape Province. SAJCN. 2005; 49 (Suppl 1): 251.

20. Dewey KG, Cohen RJ and NC Rollins Feeding of non-breastfed children 624 months of age in developing countries. Food Nutr Bull. 2004; 25 (4): $377-$ 402 .

21. Lutter C Can fortified complementary foods be socially marketed? In: meeting the challenge to improve complementary feeding. SCN News. 2003; 27: 4-9.

22. Mamiro PS, Kolsteren PW, Roberfroid D, Tatala S, Opsomer AS and JH van Camp Feeding practices and factors contributing to wasting, stunting, and iron-deficiency anaemia among 3 -23 months old children in Kilosa district, rural Tanzania. J Health Popul Nutr. 2005; 23 (3): 222-30.

23. Serlmitsos JA and H Fusco. Vitamin A fortification of sugar in Zambia 1998-2001. The MOST Project for USAID. Arlington. USA. 2001. pp 75.

24. Faber M Complementary foods consumed by 6-12-month-old rural infants in South Africa are inadequate in micronutrients. Public Health Nutr. 2005; 8 (4):373-81. 


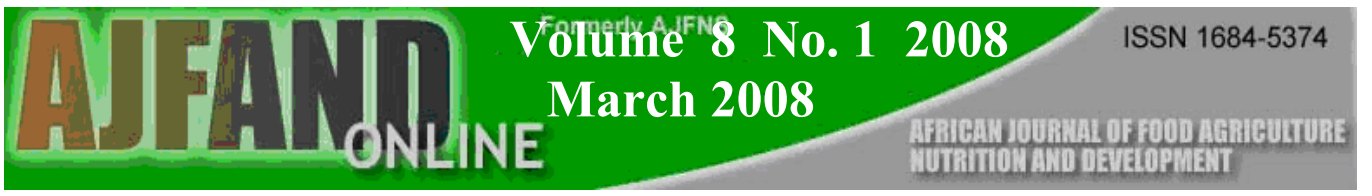

25. Dewey KG and KH Brown Update on technical issues concerning complementary feeding of young children in developing countries and implications for intervention programmes. Food Nutr Bull. 2003; 24: 5-28.

26. Gibson RS, Ferguson EL and $\mathbf{J}$ Lehrfeld Complementary foods for infant feeding in developing countries: their nutrient adequacy and improvement. Eur J Clin. Nutr. 1998; 52: 764-770.

27. Kimmons JE, Dewey KG, Haque E, Chakraborty J, Osendarp SJ and KH Brown Low nutrient intakes among infants in rural Bangladesh are attributable to low intake and micronutrient density of complementary foods. $\mathrm{J}$ Nutr. 2005; 135 (3):444-51. 